\title{
Investigation of Cytotoxic Activity of Cyanobacterial Strains Isolated from Water and Soil Samples Collected in Hanoi
}

\author{
Ngo Thi Trang ${ }^{1}$, Tong Thi Ngoc Anh ${ }^{1}$, Lai Ngoc Khanh ${ }^{1}$, Tran Thi Hang ${ }^{1}$, \\ Nguyen Thi Bich Loan ${ }^{1}$, Tran Thi Thuy Anh ${ }^{1}$, Nguyen Thuy Lien ${ }^{1}$, \\ Nguyen Thi Thu Lien ${ }^{2}$, Pham Thi Luong Hang ${ }^{1, *}$ \\ ${ }^{l}$ VNU University of Science, 334 Nguyen Trai, Thanh Xuan, Hanoi, Vietnam \\ ${ }^{2}$ Institute of Biotechnology, Hue University, Provincial Highway 10, \\ Phu Thuong, Hue City, Thua Thien Hue, Vietnam
}

Received 10 August 2021

Revised 19 August 2021; Accepted 31 August 2021

\begin{abstract}
As part of the ongoing efforts to exploit the pharmaceutical potential of domestic cyanobacteria, six strains belonging to the Nostocales order have been isolated from several sampling sites in Hanoi as prerequisite material. The cytotoxic activity evaluation based on the MTT test resulted in four extracts of two strains (HK7 and NK1111) exhibiting the inhibitory activity against HeLa cells, with $\mathrm{IC}_{50}$ values ranging from $84.6 \mu \mathrm{g} / \mathrm{mL}$ to $257.3 \mu \mathrm{g} / \mathrm{mL}$. The methanol extract of strain HK7 was further fractionated by LH-20 column chromatography to afford the $\mathrm{K} 3$ fraction, which inhibited $70 \%$ growth of HeLa cells at the concentration of $20.0 \mu \mathrm{g} / \mathrm{mL}$. In addition, the high-resolution mass spectrometric analysis detected the presence of two natural compounds in the K3 fraction. Compound 1 showed the accurate mass of $352.2633 \mathrm{Da}$, suggesting a molecular formula of $\mathrm{C}_{21} \mathrm{H}_{36} \mathrm{O}_{4}$ similar to two cytotoxic compounds 7Z-plakortide $\mathrm{H}$ or 10-gingerdiol. Compound 2 had the accurate mass of $278.1545 \mathrm{Da}$, suggesting a molecular formula of $\mathrm{C}_{16} \mathrm{H}_{22} \mathrm{O}_{4}$ similar to four cytotoxic compounds pestaloficiol $\mathrm{G}$, penicitrinol $\mathrm{E}-\mathrm{D}$, or isoversiol $\mathrm{C}$.
\end{abstract}

Keywords: Cyanobacteria, Nostocales, cytotoxic activity.

\section{Introduction}

Cyanobacteria have been considered potential candidates for drug discovery due to their diversity in biological activity and the chemical class of compounds [1-5]. In the analysis of publications from the 1970s until 2019, Demay et al. indicated that more than 1,630 unique compounds belonging to 260

\footnotetext{
"Corresponding author.

E-mail address: luonghang@hus.edu.vn

https://doi.org/10.25073/2588-1140/vnunst.5297
}

metabolite families had been isolated from cyanobacteria. These compounds exhibited 14 major types of bioactivity, including cytotoxicity, anti-inflammatory, antioxidant, antiviral, antibacterial, antifungal, enzyme inhibition activities,... The most frequent bioactivity was cytotoxic activity against various cell cancer lines accounting for $30.4 \%$ of the chemical compound families isolated from cyanobacteria [3].

Many natural compounds from cyanobacteria have been developed into new anticancer therapy and are being entered into 
preclinical trials, such as apratoxin A, coibamide A, largazole, and tasipeptins A-B [1]. In addition, the two antibody-drug conjugates (tisotumab vedotin and glembatumumab vedotin) based on cyanobacterial natural compounds have been being tested in phase I and phase II clinical trials [6]. Most notably, the cryptophycin-1 and brentuximab vedotin (based on dolastatin-10) approved by US Food and Drug Administration /European Medicines Evaluation Agency as cancer drugs, are in the current global market $[1,7,8]$. These prominent data promote further research in discovering and developing anticancer drugs from natural compounds of cyanobacteria.

In Vietnam, cyanobacteria are diversity with 61 genera and 262 species living in the rice fields and freshwater bodies [9]. However, studies on the application of cyanobacteria in Vietnam have primarily focused on their nitrogen - fixing ability rather than their biological activities. In 2017, we were the first research group in Vietnam to report the antibacterial and cytotoxic activities of extracts from isolated cyanobacteria [10]. Therefore, this study aims to extensively investigate the pharmaceutical potential of domestic cyanobacteria, focusing on isolating and exploiting the strains capable of producing cytotoxic compounds against human cervical cancer (HeLa cells).

\section{Methodology}

\subsection{Sample Sites}

The water samples were gathered from Hoan Kiem lake by using a plankton net with the mesh size of $25 \mu \mathrm{m}$; and soil samples were collected from Hoan Kiem $\left(21^{\circ} 01\right.$ ' $49.6^{\prime}$ 'N latitude and $105^{\circ} 51^{\prime} 11.7$ ''E longitude), Quoc Oai $\left(21^{\circ} 00^{\prime} 02.4^{\prime \prime} \mathrm{N}\right.$ latitude and $105^{\circ} 37^{\prime} 20.0^{\prime}$ 'E longitude), and Dong Anh (21'11'14.8' $\mathrm{N}$ latitude and $105^{\circ} 51^{\prime} 11.1$ ''E longitude) districts, Hanoi from August 2018 to December 2019. At each study site, water and soil samples were taken at three different positions.

\subsection{Cyanobacteria Isolation}

Each soil sample was suspended in liquid BG11 medium [11]; after that, $0.5 \mathrm{~mL}$ of the soil suspension or water samples were transferred onto an agar plate using the streaking technique. All petri dishes were incubated under a 12:12 light/dark cycle with white fluorescent irradiation $\left(10 \mu \mathrm{mol} . \mathrm{m}^{-2} . \mathrm{s}^{-1}\right)$ for two weeks to grow cyanobacteria. Monoclonal cyanobacterial strains were isolated using streak-plate procedure [12]. All isolated strains were deposited in the collections of cyanobacteria of the Faculty of Biology, VNU University of Science, Hanoi.

\subsection{Morphological Characterization}

The morphological examination was carried out using Zeiss Axioplan-2 fluorescence microscope equipped with a digital camera. Cell dimensions (length and width of vegetative cells, heterocytes, and akinetes) of each strain were measured from alive materials; at least thirty morphometric measurements were made per cell. Taxonomic identification was based on morphological characteristic keys presented in the classification system of Komárek et al., [13].

\subsection{Cyanobacteria Cultivation and Harvesting}

Each isolated strain was cultivated in $500 \mathrm{~mL}$ Erlenmeyer flasks containing $300 \mathrm{~mL}$ sterile BG11 medium inoculated with $5 \mathrm{~mL}$ of the three-week-old stock culture. All strains were grown at $25{ }^{\circ} \mathrm{C}$ under a 12:12 light/dark cycle with white fluorescent irradiation $\left(20 \mu \mathrm{mol} \cdot \mathrm{m}^{-2} \cdot \mathrm{s}^{-1}\right)$. The cyanobacterial biomass was harvested after seven weeks by centrifugation at $5000 \times \mathrm{g}$ for 10 minutes at $20^{\circ} \mathrm{C}$, followed by lyophilisation, and stored at $-20^{\circ} \mathrm{C}$.

\subsection{Preparation of Extracts}

For cytotoxic activity screening, freeze-dried cyanobacterial cells were successively extracted with two organic solvents following the procedure described in a previous study [10]. Firstly, $10 \mathrm{~g}$ dried biomass from each strain was homogenized in $500 \mathrm{~mL}$ ethyl acetate (EtOAc) using a mortar and pestle, followed by 
sonication for 5 minutes and stirring for 60 minutes at room temperature. Next, the homogenized solution was centrifuged at $5000 \times \mathrm{g}$ for 10 minutes at $20{ }^{\circ} \mathrm{C}$, and the supernatant was collected by filtration. The residue was extracted again with $500 \mathrm{~mL}$ EtOAc, and all supernatants were combined to obtain the EtOAc extract. Then the dried residue was successively extracted twice with $500 \mathrm{~mL}$ methanol $(\mathrm{MeOH})$ according to the same procedure to get a $\mathrm{MeOH}$ extract. Finally, the organic solvents were removed by vacuum rotary evaporation. The dried extracts were weighed and stored at $-20{ }^{\circ} \mathrm{C}$ until use.

\subsection{Chromatographies}

$50 \mathrm{~g}$ of Sephadex LH-20 was saturated in $300 \mathrm{~mL} \mathrm{MeOH}$ for 1 hour and then loaded into the column $(3.0 \mathrm{~cm}$ wide and $50.0 \mathrm{~cm}$ long). After stabilization, $500 \mathrm{mg}$ of the HK7-MeOH extract was applied on the top of the gel and eluted in $100 \% \mathrm{MeOH}$ as mobile phase [14]. The eluted fractions were analyzed by the thin layer chromatography (TLC) using silica gel $60 \mathrm{~F}_{254}$ (Merck - Germany) and a solvent system of $60 \%$ n-Hexane: $35 \%$ EtOAc: $5 \% \mathrm{MeOH}$. The TLC chromatograms were detected under UV light at wavelengths of $254 \mathrm{~nm}$ and $356 \mathrm{~nm}$.

\subsection{Liquid Chromatography - High Resolution} Mass Spectrometery (LC-HRMS)

The molecular masses of cytotoxic compounds were measured by liquid chromatography coupled with high-resolution mass spectrometry (Agilent 6530 accurate-mass Q-TOF LC/MS, Agilent technology - USA). Compounds in the $\mathrm{K} 3$ fraction were separated using the Poroshell 120 CB-C18 column, eluted in the gradient of $30-100 \%$ acetonitrile in deionized water at a flow rate of $0.3 \mathrm{~mL} / \mathrm{min}$, and detected by a diode array detector. The sample was injected in $2.0 \mu \mathrm{L}$ and analyzed in a cycle of 25 minutes [14]. The ESI-ion trap mass spectra of each compound were recorded in the positive mode in the range of $50-1600 \mathrm{~m} / \mathrm{z}$.

\subsection{Cytotoxicity Assays}

MTT (3-[4,5-dimethylthiazol-2-yl]-2,5 diphenyl tetrazolium bromide - Sigma-Aldrich, USA) kit was used for evaluation of the cytotoxic activity of cyanobacterial extracts on Human cervix epithelioid carcinoma (HeLa ATCC CCL-2). Cells were seeded in a 96-well microplate, 5000 cells/well in a $200 \mu \mathrm{L}$ culture medium (DMEM low glucose - PAN biotech, Germany) and kept at $37{ }^{\circ} \mathrm{C}$ and $5 \% \mathrm{CO}_{2} / 95 \%$ air for 24 hours. After the incubation period, each well was supplemented with $50 \mu \mathrm{L}$ cyanobacterial extracts at a final concentration of $500.0,250.0,125.0,62.5,31.2$ or $15.6 \mu \mathrm{g} / \mathrm{mL}$. For the fractions eluted from LH-20 column chromatography, the final concentration in each well was $20.0 \mu \mathrm{g} / \mathrm{mL}$. Each concentration was tested in three parallels, and the experiment was repeated three times. Paclitaxel (Sigma-Aldrich, USA) was used as a positive control at concentrations ranging from $0.003 \mu \mathrm{g} / \mathrm{mL}$ to $30 \mu \mathrm{g} / \mathrm{mL}$. After 48 hours, cells were dyed with MTT, and the optical density was measured using a Microplate reader SpectraMax Plus384 (GMI, USA) at two wavelengths of $570 \mathrm{~nm}$ and $690 \mathrm{~nm}$ [15]. The $\mathrm{IC}_{50}$ values (the concentration of extract at which $50 \%$ of cell growth was inhibited) were calculated by Excel and GraphPad Prism 8 software.

\section{Results and Discussion}

\subsection{Morphological Characterization of Isolated Strains}

The isolation process based on the different morphology features of cyanobacterial colonies led to the establishment of six monoculture strains. Of these, strain HK7 was isolated from a water sample of Hoan Kiem Lake, and all the left strains, including HK5, HK8, NK1111, NS7213, and NS7661, were derived from soil samples collected in Hoan Kiem, Quoc Oai, and Dong Anh districts, Hanoi. Morphological characteristics and morphometries of the six 
strains were observed and recorded using light microscopy equipped with a digital camera. As a result, the six isolates belong to six morphotypes based on characteristics of trichomes, heterocytes, akinetes, and vegetative cells (Figure 1 and Figure 2).

The strain HK5 was a false-branching cyanobacterium in dark blue-green colour (Figure 1C, D). Filaments were heteropolar with one to three basal heterocytes in a series. The heterocytes were subspherical to spherical with 7.5-10.0 $\mu \mathrm{m}$ long, 8.7-11.2 $\mu \mathrm{m}$ wide. Trichomes slightly constricted at the cross walls inside a thin and colorless sheath (Figure 1C). Vegetative cells compressed disc-like to shorter than wide; terminal cells were hemispherically rounded; akinetes were absent.

The strain HK7 (Figure 1A, B) was planktonic cyanobacterium in dark blue-green colour. Filaments were isopolar, slightly curved, and distinctly constricted at the cross walls in diffluent envelopes. The vegetative cells were subspherical, shorter than wide $(6.0-7.7 \mu \mathrm{m})$. The spherical heterocytes appeared in intercalary (Figure 1B) or terminal filaments (Figure 1A) with 7.0-8.0 $\mu \mathrm{m}$ in diameters. Akinetes appeared in a series with 7.5-10.0 $\mu \mathrm{m}$ in diameters in older trichomes.

The strain HK8 (Figure 1E) was in olive-grey with simple characteristics. The trichomes were isopolar without heterocytes and akineties. The vegetative cells were subspherical with 3.0-3.8 $\mu \mathrm{m}$; terminal cells were smaller with 2.5-4.0 $\mu \mathrm{m}$ long and 2.7-3.1 $\mu \mathrm{m}$ wide. The trichomes were uniserial in a firm sheath and constricted at the cross walls.

The strain NK1111 (Figure 2A, B) was in grey with isopolar filaments. The vegetative cells were cylindrical with 5.5-6.7 $\mu \mathrm{m}$ long and 4.4-5.2 $\mu \mathrm{m}$ wide. The rounded heterocytes appeared solitary in intercalary (Figure 2B) or terminal filaments (Figure 2A) with $6.6-8.3 \mu \mathrm{m}$ in diameters. Trichomes slightly constricted at the cross walls without any akinetes. Cells divided crosswise to the trichome axis resulted in regular vegetative cell chains.

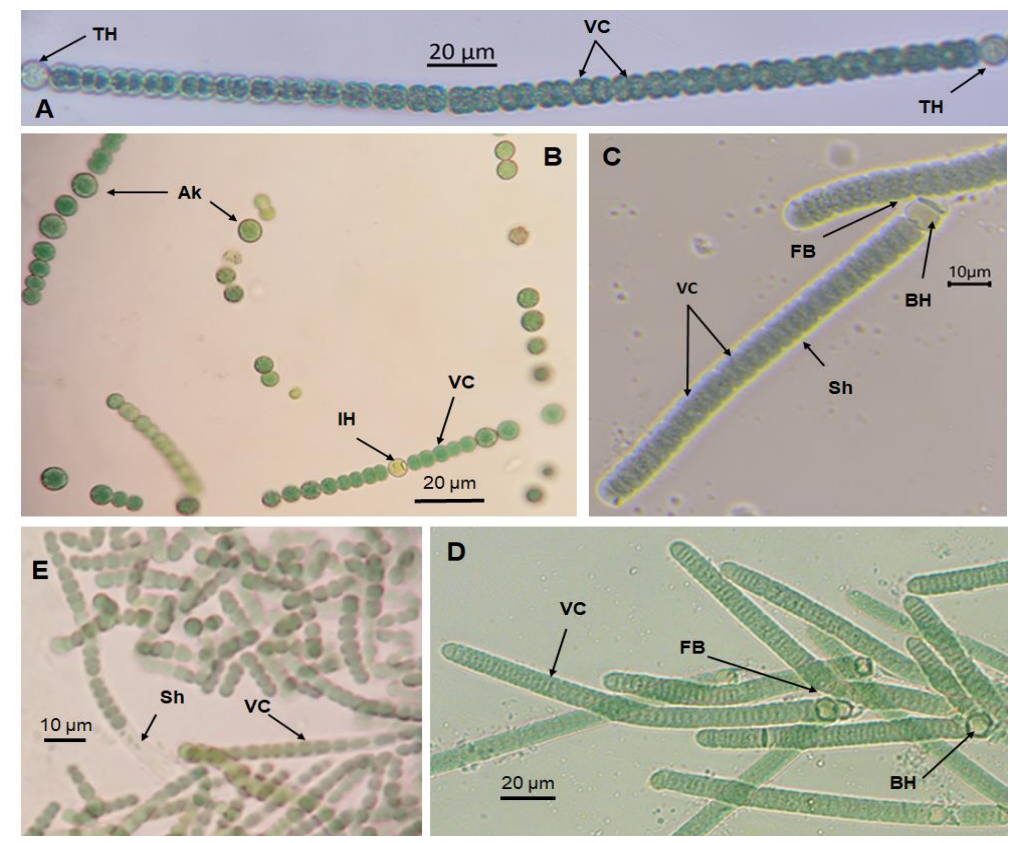

Figure 1. Morphology of strains HK7 (A, B), HK5 (C, D), and HK8 (E). TH: Terminal Heterocyte; IH: Intercalary Heterocyte; BH: Basal Heterocyte; Ak: Akinete; VC: Vegetative Cell; Sh: sheath; FB: False Branching. 


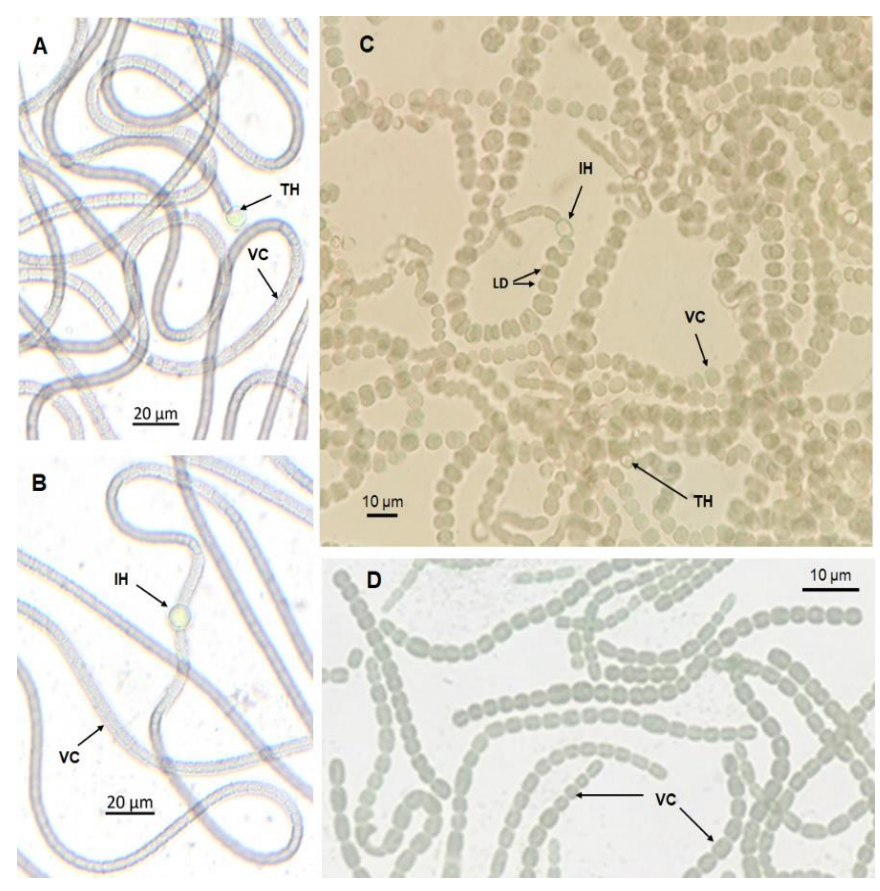

Figure 2. Morphology of strains NK1111 (A, B), NS7661 (C), and NS7213 (D)

TH: Terminal Heterocyte, IH: Intercalary Heterocyte, Ve: vegetative cells, LD: Lateral Division.

The strain NS7661 (Figure 2C) was in light brown with coiled filaments. The barrel-shaped heterocytes appeared solitary in intercalary or terminal filaments with 3.6-5.1 $\mu \mathrm{m}$ long and 3.2-4.7 $\mu \mathrm{m}$ wide. The vegetative cells were variable from disc-like to barrel-shaped and separated from each other. Cells divided irregularly in more than one plane, with numerous lateral divisions.

The strain NS7213 (Figure 2D) was pale blue-green, distinguished from others by small cell size. The vegetative cells had barrel-shaped with 2.5-3.1 $\mu \mathrm{m}$ long and 2.5-2.9 $\mu \mathrm{m}$ wide. Trichomes clearly constricted at the cross walls without envelope. Heterocytes and akinetes were not observed.

In short, the six isolates were different by several prominent characteristics indicating the diversity of cyanobacteria isolated in Hanoi. The strain HK5 was distinguished by false-branching; the HK7 was a unique strain with the development of akinetes. The strains NK1111 and NS7661 possessed intercalary or terminal heterocytes but varied in vegetative cell arrangement in filaments; the NS7661 showed irregular cell arrangement due to more than one cell division plane. Finally, the strains HK8 and NS7213 exhibited simple filament that lacked heterocytes and akinetes but differed in vegetative cell shape; vegetative cells were subspherical to spherical in strain $\mathrm{HK} 8$ but barrel-shaped in strain NS7213. Based on the morphological characteristics, all the six isolated strains were placed into the order Nostocales, in which the strain HK5 belonged to the Tolypothrix genus, the strain HK7 belonged to the Amphiheterocytum genus, and four other strains (HK8, NK1111, NS7213, and NS7661) belonged to Nostoc "sensu lato" clade $[9,13]$.

\subsection{Evaluation of Cytotoxic Activity Against HeLa Cells}

All 12 crude extracts from 6 cyanobacterial strains were assessed for cytotoxicity against human cervical cancer cells (HeLa) at six concentrations ranging from $15.6 \mu \mathrm{g} / \mathrm{mL}$ to $500 \mu \mathrm{g} / \mathrm{mL}$. The results indicated that $\mathrm{MeOH}$ 
and EtOAc extracts from two strains (HK7 and NK1111) exhibited cytotoxic activity, in which the highest inhibitory activity against HeLa was found at $\mathrm{HK} 7-\mathrm{MeOH}$ extract with $\mathrm{IC}_{50}$ values of $84.6 \mu \mathrm{g} / \mathrm{mL}$ (Table 1). On the other hand, extracts from four strains (HK5, HK8, NS7213, and NS7661) did not affect the growth and shape of HeLa cells even at the highest concentration of $500 \mu \mathrm{g} / \mathrm{mL}$; therefore, they were considered as inactive extracts.

Table 1 . The cytotoxic activity of extracts from six isolated cyanobacterial strains against HeLa cells

\begin{tabular}{|c|c|c|}
\hline Strains & Extracts & $\mathrm{IC}_{50}(\mu \mathrm{g} / \mathrm{mL})$ \\
\hline \multirow{2}{*}{ HK5 } & HK5-EtOAc & $>500.0$ \\
\hline & HK5-MeOH & $>500.0$ \\
\hline \multirow{2}{*}{ HK7 } & HK7- EtOAc & $246.1 \pm 17.1$ \\
\hline & $\mathrm{HK} 7-\mathrm{MeOH}$ & $84.6 \pm 11.8$ \\
\hline \multirow{2}{*}{ HK8 } & HK8-EtOAc & $>500.0$ \\
\hline & HK8-MeOH & $>500.0$ \\
\hline \multirow{2}{*}{ NK1111 } & NK1111-EtOAc & $157.3 \pm 7.6$ \\
\hline & NK1111-MeOH & $257.3 \pm 10.3$ \\
\hline \multirow{2}{*}{ NS7213 } & NS7213-EtOAc & $>500.0$ \\
\hline & NS7213-MeOH & $>500.0$ \\
\hline \multirow{2}{*}{ NS7661 } & NS7661-EtOAc & $>500.0$ \\
\hline & NS7661-MeOH & $>500.0$ \\
\hline $\begin{array}{l}\text { Positive } \\
\text { control }\end{array}$ & Paclitaxel & $\begin{array}{c}0.011 \\
(13.5 \mathrm{nM})\end{array}$ \\
\hline
\end{tabular}

The cytotoxic activity of methanol extracts from fresh-water cyanobacteria were mentioned in several publications. In our previous study, the $\mathrm{MeOH}$ extracts of three nostocacean strains demonstrated cytotoxic activities against MCF7 and HCT116 cells with $\mathrm{IC}_{50}$ values ranging from $47.8 \mu \mathrm{g} / \mathrm{mL}$ to $232.0 \mu \mathrm{g} / \mathrm{mL}$ [10]. The study of Karan et al., showed the cytotoxic activity of methanol extract from two other nostocacean strains (Nostoc linckia and Anabaena oryzae) against HeLa cells with $\mathrm{IC}_{50}$ values ranging from $151.4 \mu \mathrm{g} / \mathrm{mL}$ to $168.4 \mu \mathrm{g} / \mathrm{mL}$ [16]. The $\mathrm{IC}_{50}$ values (from $84.6 \mu \mathrm{g} / \mathrm{mL}$ to $257.3 \mu \mathrm{g} / \mathrm{mL}$ ) of the HK7 and NK1111 strains in this study were comparable to those of the previous studies, which indicated that the fresh-water cyanobacteria, especially the strain in the order Nostocales, were potential for producing cytotoxic compounds.

\subsection{Investigation of Cytotoxic Compounds in the HK7 Methanol Extract}

3.3.1. Fractionation of Extract by LH-20 Column Chromatography

Because of its significant cytotoxic activity, the HK7-MeOH extract was selected for the bioassay-guided isolation of active compounds. $500 \mathrm{mg}$ extract was loaded on the top of the Sephadex LH-20 column and eluted in methanol $100 \%$. As a result, 28 eluted fractions were collected and analyzed using TLC. Based on the similar pattern of the TLC chromatograms, the 28 fractions were combined into nine fractions (named K1 - K9). The pattern components of K1 - K9 fractions on TLC chromatograms observed at the wavelengths of $254 \mathrm{~nm}$ and $365 \mathrm{~nm}$ are shown in Figure 3. All nine fractions were tested for cytotoxic activity against HeLa cell line at a $20 \mu \mathrm{g} / \mathrm{mL}$ concentration. The result showed that the fraction K3 inhibited 70\% growth of HeLa cells (cells were shrunk or detached) (Figure 4B), while the other eight fractions had minor effects on the growth and shape of HeLa cells (Figure 4C).

Like the TLC chromatograms detected at the wavelengths of $365 \mathrm{~nm}, \mathrm{~K} 3$ possessed the blue band at $\mathrm{Rf}_{1}=0.15$ and was the fraction with the minor chlorophyll derivatives (only one fluorescence band appeared at $\mathrm{Rf}_{2}=1.0$ ) compared to other fractions (Figure 3B, D). In addition, none of the bands was detected at the wavelengths of $254 \mathrm{~nm}$ (Figure 3A), indicating that most of the impurities were eliminated from this fraction. Therefore, the fraction was clean enough to analyse the active component by high-performance liquid chromatography equipped with mass spectrometry. 


\subsubsection{Detection of Bioactive Compounds by LC-HRMS}

The fraction K3 was analyzed by LC-HRMS in the gradient of $30-100 \%$ acetonitrile in deionized water. The HPLC chromatogram at short wavelength of $210 \mathrm{~nm}$ showed two main compounds in $\mathrm{K} 3$ fraction at retention times of $11.18 \mathrm{~min}$ and $13.65 \mathrm{~min}$, respectively (Figure 5A). Compound 1 eluted at retention times of $11.18 \mathrm{~min}$ had a mass to charge of
$353.2706 \mathrm{~m} / \mathrm{z}$ in $[\mathrm{M}+\mathrm{H}]^{+}$mode (Figure 5B), and the accurate mass (experimental mass) of this compound was measured as 352.2633 Dalton (Da). Compound 2 eluted at 13.65 min exhibited a mass to charge of $279.1618 \mathrm{~m} / \mathrm{z}$ in $[\mathrm{M}+\mathrm{H}]^{+}$mode (Figure 5C), and its accurate mass was measured as 278.1545 Da. Other peaks that appeared at the retention time range of 18.0-19.0 min showed no mass, indicating non-significant compounds.
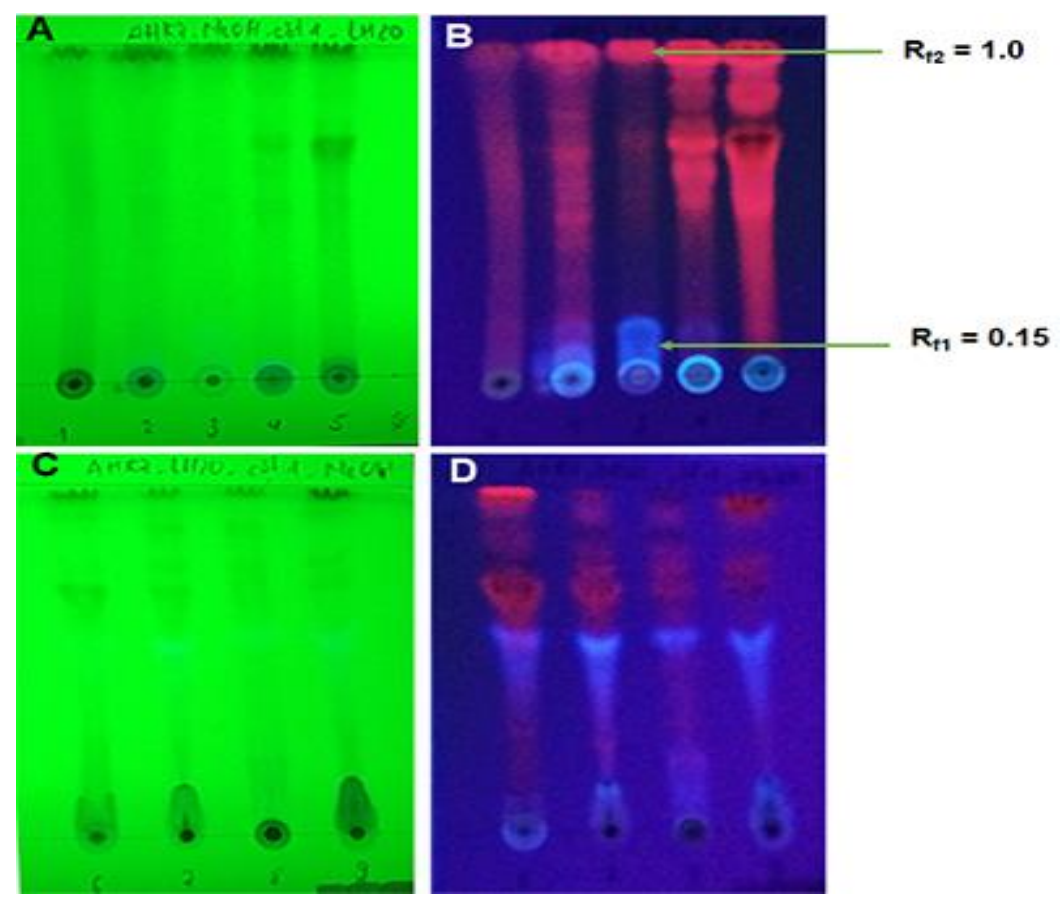

Figure 3. TLC chromatograms of $\mathrm{K} 3-\mathrm{K} 9$ fractions.

Mobile phase: $60 \% \mathrm{n}-\mathrm{Hexane}: 35 \%$ EtOAc: $5 \% \mathrm{MeOH}$; K3-K5 fractions at wavelengths of $254 \mathrm{~nm}$ (A) and $365 \mathrm{~nm}(\mathrm{~B}) ; \mathrm{K} 6-\mathrm{K} 9$ fractions at wavelengths of $254 \mathrm{~nm}$ (C) and $365 \mathrm{~nm}(\mathrm{D})$.

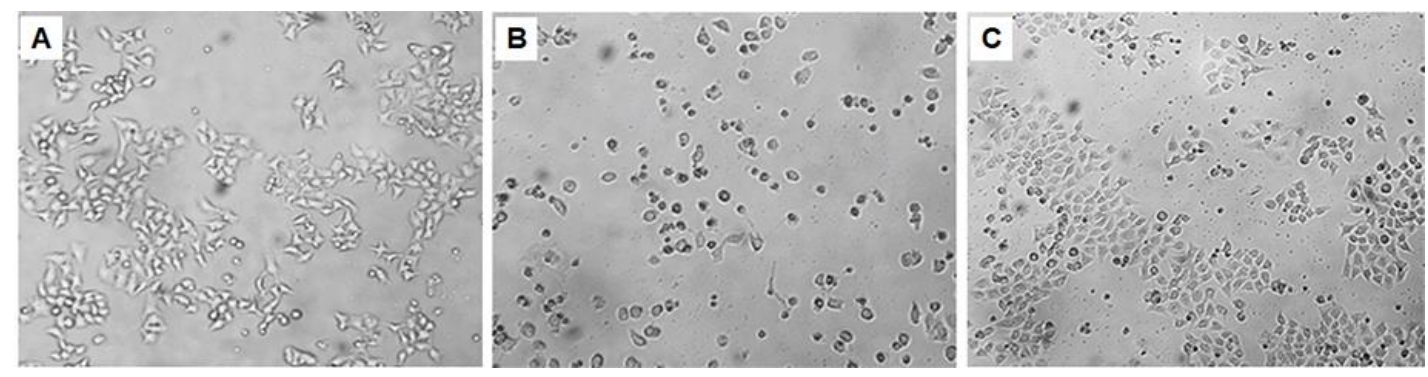

Figure 4. Morphology of Hela cells in cytotoxic test.

A) Untreated cells; B) Cells treated with fraction K3; C) Cells treated with fraction K4. 

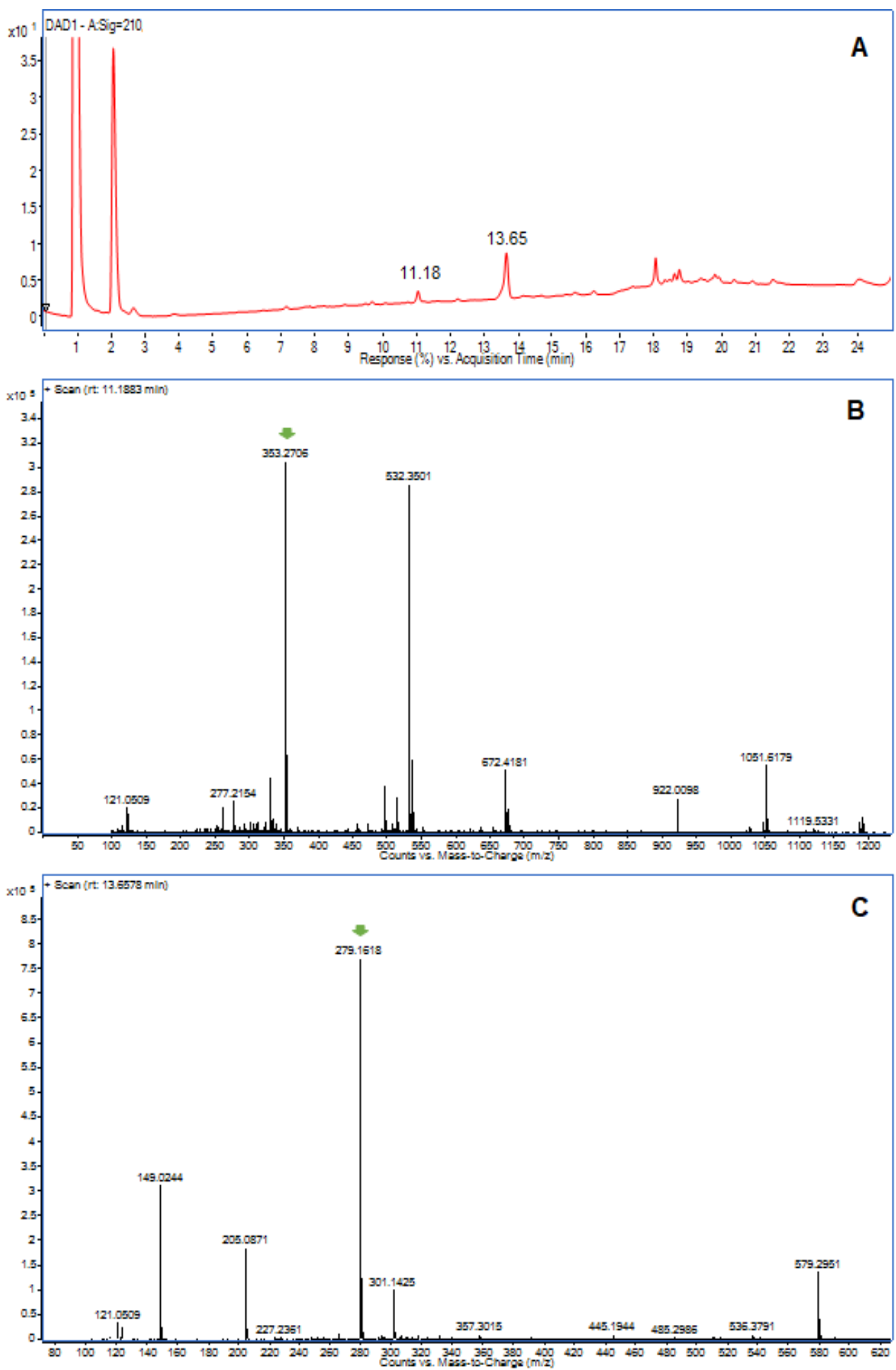

Figure 5. Mass spectra of bioactive compounds in fraction K3.

LC chromatogram at wavelength of $210 \mathrm{~nm}(\mathrm{~A})$;

mass to charge of Compound 1 (B) and Compound 2 (C). 


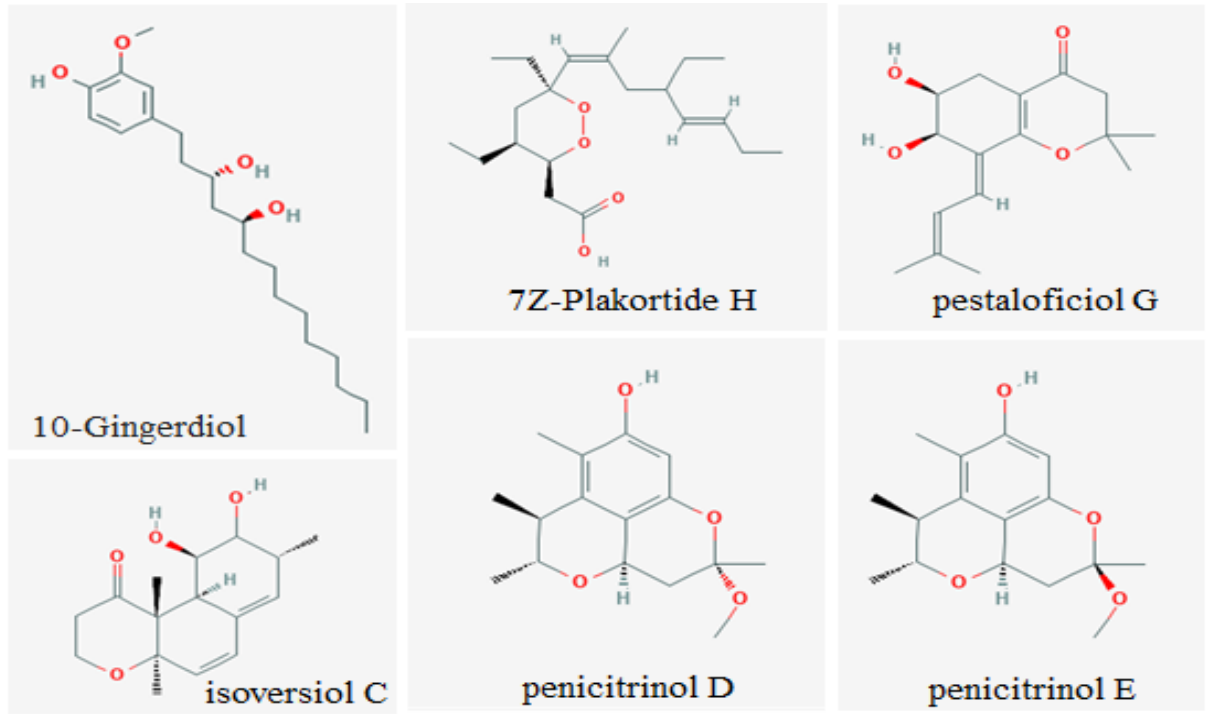

Figure 6. Possible structures for Compound 1 (7Z-plakortide H or 10-gingerdiol) and for Compound 2 (pestaloficiol G, penicitrinol E-D, or isoversiol C).

Source: https://pubchem.ncbi.nlm.nih.gov.

Based on the accurate masses, the searches for possible natural compounds were performed on two updated websites http://dnp.chemnetbase.com and https://pubchem.ncbi.nlm.nih.gov, in August 2021. As a result, three compounds (7Z-plakortide $\mathrm{H}, 10$-gingerdiol, and ebelactone $\mathrm{B}$ ) had an exact mass (theoretical mass) of 352.2613 Da with the formula of $\mathrm{C}_{21} \mathrm{H}_{36} \mathrm{O}_{4}$ which was the highest match to the accurate mass of Compound 1 (352.2633 Da). Of these, 7Z-plakortide $\mathrm{H}$ and 10-gingerdiol have been considered as cytotoxic compounds against non-small-cell lung cancer cell line/melanoma cell line [17] and ovarian cancer cell line [18], respectively; while the ebelactone $\mathrm{B}$ exhibited esterase and lipase inhibitory activity [19]. Therefore, based on the bioactivity and the exact mass, the possible chemical name for Compound 1 would be 7Z-plakortide $\mathrm{H}$ or 10-gingerdiol, as illustrated in Figure 6.

Nine compounds had an exact mass of $278.1518 \mathrm{Da}$ with the formula of $\mathrm{C}_{16} \mathrm{H}_{22} \mathrm{O}_{4}$, which was the highest match to the accurate mass of compound 2 (278.1545 Da). Of these, two compounds (truncateol and pestaloficiol A) showed antiviral activities [20, 21]; three compounds (oblongolide G, hyrtiosenolide A, and guignardone G) displayed antibacterial activities [22-24]; and four compounds (pestaloficiol G, penicitrinol E-D, and isoversiol C) exhibited cytotoxic activities [25-27]. Thus, based on the bioactivity and the exact mass, the possible chemical name for Compound 2 would be pestaloficiol G, penicitrinol E-D, or isoversiol C, as illustrated in Figure 6.

Interestingly, all the reported compounds had similar exact masses and formulas with those of the two compounds detected in this study were isolated from other organisms (plant, sponge, or fungi) rather than cyanobacteria. Therefore, it is worthy to conclude that this is the first time these possible structures have been exploited in cyanobacteria.

\section{Conclusion}

Six cyanobacterial strains were isolated from water and soil samples collected at three locations in Hanoi. They showed the morphology diversity in characteristics of trichomes, heterocytes, akinetes, and vegetative cells; belonging to order Nostocales. Two out of the six strains exhibited cytotoxic activity against $\mathrm{HeLa}$ cells, with $\mathrm{IC}_{50}$ values of extracts 
ranging from $84.6 \mu \mathrm{g} / \mathrm{mL}$ to $257.3 \mu \mathrm{g} / \mathrm{mL}$. In addition, the bioassay-guided isolation of the HK7-MeOH extract led to the K3 fraction, which inhibited $70 \%$ growth of HeLa cells at the concentration of $20.0 \mu \mathrm{g} / \mathrm{mL}$. The LC-HRMS analysis of fraction K3 recognized two natural compounds; Compound 1 showed the accurate mass of $352.2633 \mathrm{Da}$, suggesting a molecular formula of $\mathrm{C}_{21} \mathrm{H}_{36} \mathrm{O}_{4}$, and Compound 2 had the accurate mass of $278.1545 \mathrm{Da}$, suggesting a molecular formula of $\mathrm{C}_{16} \mathrm{H}_{22} \mathrm{O}_{4}$. The detailed structures of these compounds would be elucidated by nuclear magnetic resonance measurement in the subsequent study.

\section{Acknowledgements}

This research was funded by Vietnam National University, Hanoi (VNU), under Project QG.19.04.

The authors thank Dr. Nguyen Xuan Nhiem from the Institute of Marine Biochemistry for measuring the mass spectra of compounds.

\section{References}

[1] K. V. Bajpai, S. Shukla, S. M. Kang, S. K. Hwang, X. Song, Y. S. Huh, Y. K. Han, Developments of Cyanobacteria for Nano-Marine Drugs: Relevance of Nanoformulations in Cancer Therapies, Mar, Drugs, Vol.16, 2018, pp. 179-201.

[2] G. E. Chlipala, S. Mo, J. Orjala, Chemodiversity in Freshwater and Terrestrial Cyanobacteria - a Source for Drug Discovery, Curr, Drug Targets, Vol. 12, 2011, pp. 1654-1673.

[3] J. Demay, C. Bernard, A. Reinhardt, B. Marie, Natural Products from Cyanobacteria: Focus on Beneficial Activities, Mar, Drugs, Vol. 17, 2019, pp. 320-369.

[4] R. B. Dixit, M. R. Suseela, Cyanobacteria: Potential Candidates for Drug Discovery, Antonie Van Leeuwenhoek, Vol. 103, 2013, pp. 947-961.

[5] R. K. Singh, S. P. Tiwari, A. K. Rai, T. M. Mohapatra, Cyanobacteria: an Emerging Source for Drug Discovery, J. Antibiot (Tokyo), Vol. 64, 2011, pp. 401-412.

[6] B. E. de Goeij, J. M. Lambert, New Developments for Antibody-Drug Conjugate-based Therapeutic Approaches, Curr, Opin, Immunol, Vol. 40, 2016, pp. 14-23.
[7] V. A. Verma, T. H. Pillow, L. DePalatis, G. Li, G. L. Phillips, A. G. Polson, H. E. Raab, S. Spencer, B. Zheng, The Cryptophycins as Potent Payloads for Antibody Drug Conjugate, Bioorg, Med, Chem, Lett, Vol. 25, 2015, pp. 864-868.

[8] A. Younes, N. L. Bartlett, J. P. Leonard, D. A. Kennedy, C. M. Lynch, E. L. Sievers, A. F. Torres, Brentuximab Vedotin (SGN-35) for relapsed CD30-positive lymphomas, the New England Journal of Medicine, Vol. 36, 2010, pp. 1812-1821.

[9] D. T. Duong, Classification of Vietnamese Cyanobacteria, Agricultural Institute Public Publishing House, 1996, pp. 110-120 (in Vietnamese).

[10] H. T. L. Pham, L. T. T. Nguyen, A. T. Duong, D. T. T. Bui, Q. T. Doan, H. T. T. Nguyen, S. Mundt, Diversity and Bioactivities of Nostocacean Cyanobacteria Isolated from Paddy Soil in Vietnam, Syst, Appl, Microbiol, Vol. 40, 2017, pp. 470-481.

[11] R. Rippka, R. Duruelles, J. B. Waterbury, M. Herbman, R. Y. Stanier, Generic Assignments, Strain Histories and Properties of Pure Cultures of Cyanobacteria, J. Gen, Microbiol, Vol. 111, 1979, pp. 1-61.

[12] R. A. Andersen, M. Kawachi, Traditional Microalgae Isolation Techniques, in Algal Culturing Techniques, Elsevier, Amsterdam, 2005, pp. 83-100.

[13] J. Komárek, J. Kaštovský, J. Mareš, J. R. Johansen, Taxonomic Classification of Cyanoprokaryotes (Cyanobacterial Genera) 2014, Using a Polyphasic Approach, Preslia, Vol. 86, 2014, pp. 295-335.

[14] M. Preisitsch, K. Harmrolfs, H. T. L. Pham, S. E. Heiden, A. Fussel, C. Wiesner, A. Pretsch, M. Swiatecka-Hagenbruch, T. H. Niedermeyer, R. Muller, S. Mundt, Anti-MRSA-acting Carbamidocyclophanes H-L from the Vietnamese Cyanobacterium Nostoc sp. CAVN2, J. Antibiot (Tokyo), Vol. 68, 2015, pp. 600-615.

[15] L. T. B. Nguyen, T. K. Kieu, T. L. Nguyen, T. K. T. Nguyen, H. Q. Nguyen, T. H. Pham, M. Muller, A. Nachtergael, P. Duez, T. D. Nguyen, Toxicity and Anti-Proliferative Properties of Anisomeles Indica Ethanol Extract on Cervical Cancer HeLa Cells and Zebrafish Embryos, Life, Vol. 11, 2021, pp. 257-272.

[16] T. Karan, A. Aydin, Anticancer Potential and Cytotoxic Effect of some Freshwater Cyanobacteria, Trop, J. Pharm, Res, Vol. 17, No. 11, 2018, pp. 2183-2188.

[17] T. Schirmeister, S. Oli, H. Wu, G. D. Sala, V. Costantino, E. J. Seo, T. Efferth, Cytotoxicity of Endoperoxides from the Caribbean Sponge Plakortis Halichondrioides Towards Sensitive and 
Multidrug-Resistant Leukemia Cells: Acids vs. Esters Activity Evaluation, Mar, Drugs, Vol. 15, No. 3, 2017, pp. 63-74.

[18] A. Rasmussen, K. Murphy, D. W. Hoskin, 10-Gingerol Inhibits Ovarian Cancer Cell Growth by Inducing G2 Arrest, Adv, Pharm, Bull, Vol. 9, No. 4, 2019, pp. 685-689.

[19] Y. Nonaka, H. Ohtaki, E. Ohtsuka, T. Kocha, T. Fukuda, T. Takeuchi, T. Aoyagi, Effects of Ebelactone B, a Lipase Inhibitor, on Intestinal Fat Absorption in the Rat, J. Enzyme Inhib, Vol. 10, No. 1, 1996, pp. 57-63.

[20] L. Liu, R. Tian, S. Liu, X. Chen, L. Guo, Y. Che, Pestaloficiols A-E, Bioactive Cyclopropane Derivatives from the Plant Endophytic Fungus Pestalotiopsis Fici, Bioorg, Med, Chem, Vol. 16, No. 11, 2008, pp. 6021-6026.

[21] Z. Yang, S. Longlong, L. Dong, P. Proksch, Z. Demin, L. Wenhan, A. N. Truncateols, New Isoprenylated Cyclohexanols from the Sponge-associated Fungus Truncatella Angustata with Anti-H1N1 Virus Activities, Tetrahedron, Vo. 71, No. 18, 2015, pp. 2708-2718.

[22] J. Dai, K. Krohn, D. Gehle, I. Kock, U. Flörke, H. J. Aust, S. Draeger, B. Schulz, J. Rheinheimer, New Oblongolides Isolated from the Endophytic Fungus Phomopsis sp. from Melilotus Dentata from the Shores of the Baltic Sea, Eur, J. Org, Chem, Vol. 18, 2005, pp. 3351-3359.

[23] W. L. Mei, B. Zheng, Y. X. Zhao, H. M. Zhong, X. L. W. Chen, Y. B. Zeng, W. H. Dong, J. L. Huang, P. Proksch, H. F. Dai, Meroterpenes from Endophytic Fungus A1 of Mangrove Plant Scyphiphora Hydrophyllacea, Mar, Drugs, Vol. 10, No. 9, 2012, pp. 1993-2001.

[24] D. T. Youssef, A. N. Singab, R. W. van Soest, N. Fusetani, Hyrtiosenolides A and B, Two New Sesquiterpene Gamma-methoxybutenolides and a New Sterol from a Red Sea Sponge Hyrtios Species, J. Nat, Prod, Vol. 67, No. 10, 2004, pp. 1736-1739.

[25] L. Chen, W. Liu, X. Hu, K. Huang, J. L. Wu, Q. Q. Zhang, Citrinin Derivatives from the Marine-Derived Fungus Penicillium citrinum, Chem, Pharm, Bull, Vol. 59, No 4, 2011, pp. 515-517.

[26] N. Cho, T. T. Ransom, J. Sigmund, T. Tran, R. H. Cichewicz, M. Goetz, J. A. Beutler, Growth Inhibition of Colon Cancer and Melanoma Cells by Versiol Derivatives from a Paraconiothyrium Species, J. Nat, Prod, Vol. 80, No. 7, 2017, pp. 2037-2044.

[27] L. Liu, S. Liu, S. Niu, L. Guo, X. Chen, Y. Che, Isoprenylated Chromone Derivatives from the Plant Endophytic Fungus Pestalotiopsis fici, J. Nat, Prod, Vol. 72, No. 8, 2009, pp. 1482-1486. 